\title{
Jubiläum in Ischgl
}

FVDZ-Fortbildungskongress. Im Kalender für 2018 sollte bei Zahnärzten und Praxismitarbeitern ein Termin nicht fehlen: Vom 18. bis 23. Februar lädt der Freie Verband Deutscher Zahnärzte (FVDZ) bereits zu seinem 50 . Winterkongress ein, der erneut im österreichischen Ischgl stattfindet.

AUTOR: FVDZ
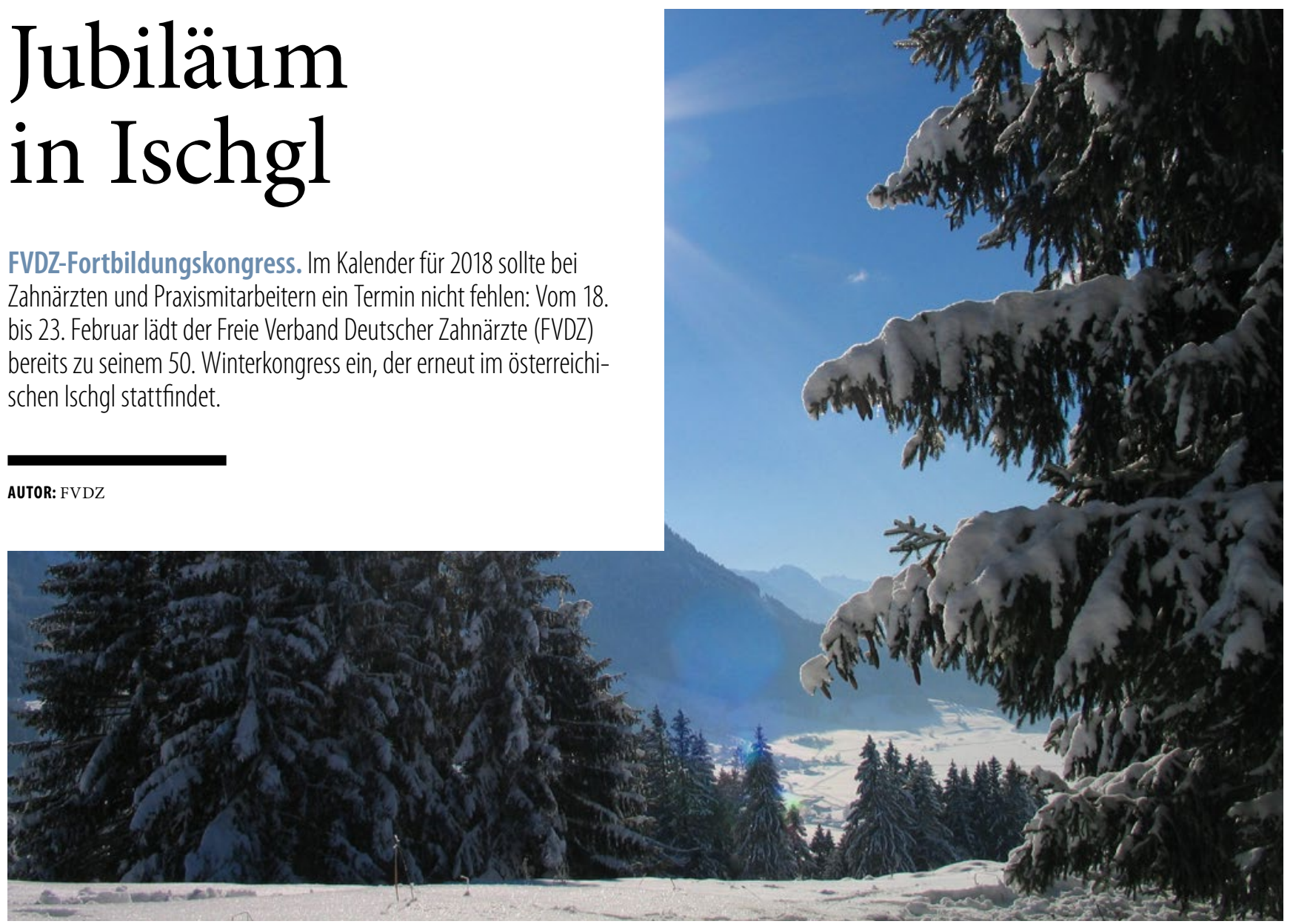

International renommierte Referenten stellen neue Behandlungskonzepte und Diagnoseverfahren vor. Klinische und praxisrelevante Grundlagen stehen ebenso wie mannigfaltiges Expertenwissen auf dem Programm. Das Besondere: Auf die Teilnehmer warten eine sechstägige Fortbildung in familiärer Atmosphäre, die Möglichkeit zum Netzwerken vor der faszinierenden Kulisse der Tiroler Bergwelt und vielfältige Freizeitmöglichkeiten. Ein weiterer Höhepunkt: Bei der Eröffnungsveranstaltung berichtet der prominente Gast Reiner Calmund, wie man kompetent und leidenschaftlich erfolgreich sein kann. Der ehemalige deutsche Fußballfunktionär ist mittlerweile als Experte,
Moderator und Buchautor bekannt und fokussiert sich in seinem Vortrag auf Parallelen und Unterschiede von Profifußballclubs und Wirtschaftsunternehmen mit den Schwerpunkten Marketing, Teamgeist, Führung und Nachwuchsarbeit.

Studentischen Mitgliedern ermöglicht der Freie Verband wieder eine kostenfreie Teilnahme am Winterkongress sowie ein attraktives Rahmenprogramm. Insgesamt werden 20 Wochenkarten verlost. Zudem sponsert der FVDZ die Unterkunft für sechs Nächte inklusive Frühstück. Das Gewinnspiel läuft bis zum 31. Dezember 2017.

WEITERE INFORMATIONEN ERHALTEN SIE UNTER WWW.FVDZ.DE/ISCHGL2018.
REINER

CALMUND

ÜBER LEIDEN-

SCHAFT UND KOMPETENZ 